\title{
A CREW Change
}

\section{Thanks Dave!}

Oceanography was built from the visions of a team that Dave Brooks put together several years ago. They found the proper clay and sculpted it into a publication that has quickly brought an identity to itself and The Oceanography Society. That is the best reward that Dave, Therese, Letty, Norman, Karen and the others could receive. However, they have also the appreciation of those of us who watched and read. The editorial staffs that follow will make small adjustments, but primarily we will be hoping to maintain a level of quality equal to our predecessors. Thanks for giving us something to shoot for.

\section{What Small Adjustments?}

Oceanography will remain fundamentally the same publication. However, natural evolution usually leads to successful changes, and in this vein we will seek the appropriate modifications. Annual publication will increase from twice to thrice. Peer review will be intensified. Associate editors from outside the US will be appointed. Active attempts will be made to maintain the interdisciplinary character of the publication, as well as to examine all reaches of the ocean, including coastal waters.

\section{What's the Deal With This Issue?}

A year ago, as an associate editor, I was asked to bring more coastal visibility to Oceanography. I began orchestrating a series about an interdisciplinary project near and dear to me. Coincidently the articles became ready for publication in this, my first issue as editor.

In the future we expect most issues of Oceanography to contain mixtures of articles addressing a range of topics. However, from time to time certain themes will be examined. We are always interested in receiving relevant manuscripts for publication and in hearing about potential topics for theme issues. Please contact me.

—Chuck Nittrouer

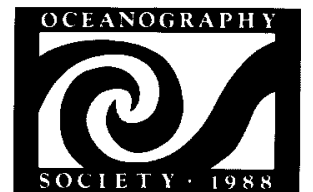

THE OCEANOGRAPHY SOCIETY

1775 Massachusetts Avenue N.W., Suite 700 Washington, D.C. 20036

(202) 234-2109; Telefax: (202) 234-9538 omnet: OCEANOGRAPHY SOCIETY

OFFICERS

D. James Baker, President Arnold L. Gordon, President-Elect Melbourne G. Briscoe, Secretary David L Evans, Treasurer

COUNSELORS

Sallie W. Chisholm, Biology

Curtis A. Collins, Physics

Richard Jahnke, Chemistry

Kevin D. Leaman, Applied Technology Constance A. Sancetta, Geology and Geophysics

W. Stanley Wilson, At-Large

Charles A. Nittrouer, ex officio

EXECUTIVE DIRECTOR Judi Powell

\section{Oceanography}

EDITOR

Charles A. Nittroue

Marine Sciences Research Center State University of New York

Stony Brook, New York 11794-5000

(516) 632-8651; C.NITTROUER Telefax: (516) 632-8820

EDITORIAL ASSISTANT Michele MCTernan Marine Sciences Research Center State University of New York Stony Brook, NY 11794-5000 (516) 632-8651

ASSOCIATE EDITORS James Ammerman (Biology)

Texas A\&M University

College Station, TX 77843

(409) 845-5105; J.AMMERMAN

Ellen R.M. Druffel (Chemistry) Woods Hole Oceanographic Institution Woods Hole, MA 02543 (508) 548-1400; E.DRUFFEL

Donald B. Olson (Physics) RSMAS

University of Miam

Miami, FL 33149

(305) 361-4074; D.OLSON.RSMAS

Aichard W. Spinrad (Technology and Instruments) Office of Naval Research, Code 1123 Arlington, VA 22217

(202) 696-4732; R.SPINRAD

PRINTER

Lancaster Press Lancaster, PA 